\title{
Hypoaldosteronism in three sibs due to 18-dehydrogenase deficiency
}

\author{
W. HAMILTON, A. E. McCANDLESS, J. T. IRELAND, and C. E. GRAY \\ From the University Departments of Child Health, Liverpool and Glasgow
}

\begin{abstract}
Hamilton, W., McCandless, A. E., Ireland, J. T., and Gray, C. E. (1976). Archives of Disease in Childhood, 51, 576. Hypoaldosteronism in three sibs due to 18-dehydrogenase deficiency. Three sibs all presented in the early neonatal period with a salt-losing syndrome. The salt-losing form of congenital adrenal hyperplasia was diagnosed and appropriate treatment with glucocorticosteroids, mineralocorticosteroids, and additional dietary salt started. Although early life was maintained with difficulty, with age all 3 children required decreasing amounts of replacement steroids to maintain normal plasma electrolyte balance. They were reinvestigated at the ages of 15 years and 8 years (twins), when cortisol synthesis and metabolism proved normal, but aldosterone synthesis was blocked by deficiency of 18-dehydrogenase. Rational treatment of these cases of a salt-losing syndrome in which aldosterone synthesis alone is blocked due to lack of the enzyme 18-dehydrogenase requires the administration of a mineralocorticosteroid drug only. Since deoxycorticosterone (acetate or pivalate) requires intramuscular administration, as life-long therapy oral fludrocortisone is preferable. Although fludrocortisone has glucocorticoid activity, the 'hydrocortisone equivalent' effect of the small dosage used was unlikely to inhibit either pituitary corticotrophin or growth hormone production.
\end{abstract}

Salt-loss of adrenal origin is recognized as a feature of $3 \beta$-hydroxysteroid dehydrogenase deficiency and the complete form of 21-hydroxylase deficiency. It is also present in patients with lipoid adrenal hyperplasia (thought to be due to deficiency of cholesterol $20 \alpha$-hydroxylase) and in those with congenital adrenal hypoplasia. In all these patients aldosterone synthesis is inadequate, but since the cortisol pathway is also affected there is concomitant defective synthesis of cortisol. Less commonly an enzyme defect in the mineralocorticoid pathway alone interrupts the synthesis of aldosterone leaving cortisol production unimpaired. Clinical examples of this have been described by Visser and Cost (1964) and David, Golan, and Drucker (1968).

In the neonatal period, irrespective of the specific aetiology, salt-loss is of sudden onset usually between the 10th and 14th day. When cortisol synthesis is normal, adrenocortical hyperplasia does not occur and therefore there is no excess of adrenal androgen to cause masculinization of the

Received 17 November 1975. female external genitalia or macrogenitosomia praecox in the male. In the absence of abnormal genitalia, the sudden onset of salt-loss is not anticipated because attention is not directed to a possible adrenocortical pathology. Also because of the seeming rarity of enzyme defects in the mineralocorticoid pathway alone, patients may in the past have been erroneously considered as examples of a salt-losing form of the adrenogenital syndrome and treated with both mineralocorticoid and glucocorticoid replacement therapy. Unless the error is detected reasonably early there is a risk that such patients will be unnecessarily dwarfed by virtue of of the glucocorticoid administration. On the other hand, since there is no real cortisol lack and no excess of adrenal androgens, some cases may have been managed with ever decreasing doses of exogenous glucocorticoids and thus may have attained normal stature.

We present 3 sibs with a salt-losing syndrome who were initially considered as examples of the adrenogenital syndrome with salt-loss, but who were later shown to have defective aldosterone synthesis due to failure of 18-dehydrogenase. 


\section{Hypoaldosteronism in three sibs due to 18-dehydrogenase deficiency}

\section{Patients}

Family history. The paternal grandparents were first cousins. The parents are unrelated, the mother has epilepsy and had hydantoin and phenobarbitone throughout all her pregnancies. There were 5 successful pregnancies, the fifth resulting in twins. 3 of the children are healthy, the second, a male, and the last born, a pair of twins, are affected.

Case 1. A boy, born at term (31 July 1956) by vertex delivery weighing $2.97 \mathrm{~kg}$. At the end of the second week he started to vomit and rapidly lost weight. Common causes for these features were excluded but because of a possible slight scrotal pigmentation, the serum electrolytes were estimated, when raised serum potassium and lowered sodium and chloride levels were noted. Because of sudden deterioration, further investigation was deferred and an intravenous glucose/ saline infusion begun as a life-saving procedure. Failure to obtain a 24-hour collection of urine in the maternity unit necessitated transfer to Alder Hey Hospital on the 20th day of life. At that time the serum electrolytes were sodium $104 \mathrm{mmol} / 1$; potassium $7.9 \mathrm{mmol} / \mathrm{l}$; chloride $90 \mathrm{mmol} / \mathrm{l}$. A 24-hour urine collection contained 17-oxosteroids $1.26 \mathrm{mg}(4.37 \mu \mathrm{mol})$ and total 17-hydroxycorticosteroids $2.5 \mathrm{mg}(8.68 \mu \mathrm{mol})$. Pregnanetriol was not estimated. Rapid clinical deteriorattion followed, necessitating intramuscular cortisone acetate $25 \mathrm{mg}$ daily, in divided doses, sodium chloride $1 \mathrm{~g}$ per day orally, and deoxycorticosterone (DOCA) $2.5 \mathrm{mg} /$ day intramuscularly. However, maintenance of normal serum electrolytes was not achieved until DOCA was increased to $12 \cdot 5 \mathrm{mg}$ daily and sodium chloride to $2 \mathrm{~g}$ daily.

Between the third and fifth months of life oral fludrocortisone was introduced to replace the intramuscularly administered DOCA and balance was eventually achieved with oral cortisone acetate $37.5 \mathrm{mg}$ daily, fludrocortisone $0.2 \mathrm{mg}$ daily and sodium chloride $2 \mathrm{~g}$ daily. Occasional increases in this dosage schedule were necessary during acute respiratory infections. During the second year of life the blood pressure rose. This necessitated a reduction in the administered steroids to dexamethasone $0.75 \mathrm{mg}$ daily, fludrocortisone $0.2 \mathrm{mg}$ daily, and sodium chloride $3 \mathrm{~g}$ daily. At age 3 years his height was $78 \mathrm{~cm}$ (<3rd centile) and weight $8.18 \mathrm{~kg}$ ( $<3$ rd centile). Slow progress continued throughout childhood and it was possible to reduce therapy to dexamethasone $0.25 \mathrm{mg}$ daily, fludrocortisone $0.1 \mathrm{mg}$ daily, and sodium chloride $2 \mathrm{~g}$ three times daily. At age 9.8 years his height was $118 \mathrm{~cm}$ ( $<3$ rd centile) and his bone age $9 \cdot 1$ years. Because of the marked failure to gain in height it was decided to attempt further reduction in glucocorticosteroid dosage and, indeed, dexamethasone was completely withdrawn at age 10 years without ill effects. Subsequent to withdrawal of dexamethasone the plasma cortisol level was normal and remained so though after tetracosactrin stimulation the increment increase in plasma cortisol was from $5 \mu \mathrm{g}$ to $24 \mu \mathrm{g} / 100 \mathrm{ml}(138-663 \mathrm{nmol} / \mathrm{l})$. At age 13 years fludrocortisone was omitted and he was maintained on oral sodium chloride ( $5 \mathrm{~g}$ three times daily) alone. His general condition remained satisfactory, his height was then $130 \mathrm{~cm}$ (>3rd centile), weight $32 \cdot 7 \mathrm{~kg}$ (10th centile), and bone age $11 \cdot 3$ years. He was reinvestigated at $15 \frac{1}{2}$ years, his height then being $147 \mathrm{~cm}(>3 \mathrm{rd}$ centile), weight $33.5 \mathrm{~kg}$ ( $3 \mathrm{rd}$ centile), and bone age 13.4 years (Fig. 1a). At the time of reinvestigation all steroids had been withdrawn for more than 2 years.

Case 2. A girl was the first of twins born by breech delivery at 40 weeks (10 February 1964). Birthweight $2.56 \mathrm{~kg}$. At age 10 days she suddenly started to vomit all feeds. On that day the serum sodium and chloride concentration was depressed with markedly raised serum potassium. Urine analysis for steroid metabolites per $24 \mathrm{~h}$ gave 17-oxosteroids $0.3 \mathrm{mg}(1.04 \mu \mathrm{mol})$, 17-hydroxycorticosteroids $0.8 \mathrm{mg}(2 \cdot 78 \mu \mathrm{mol})$, and pregnanetriol $0.14 \mathrm{mg}(0.42 \mu \mathrm{mol})$. Because of rapid clinical deterioration further investigation was postponed and because of the similarity of her clinical condition to that of her elder sib she was assumed to be an example of the salt-losing form of the adrenogenital syndrome. Her condition stabilized on dexamethasone $0.25 \mathrm{mg}$ three times daily, fludrocortisone $0.05 \mathrm{mg}$ twice daily, intramuscular DOCA $10 \mathrm{mg}$ daily, and oral sodium chloride $1.5 \mathrm{~g}$ daily. It was impossible to reduce significantly the above drug schedule and she was ultimately discharged from hospital at age 7 months on dexamethasone $0.625 \mathrm{mg}$ daily, fludrocortisone 0.1 $\mathrm{mg}$ daily, sodium chloride $3 \mathrm{~g}$ daily, and intramuscular DOCA $10 \mathrm{mg}$ daily. She then weighed $5.4 \mathrm{~kg}$.

During the following months DOCA was gradually withdrawn without detriment and at age 1 year the dosage schedule was dexamethasone $0.625 \mathrm{mg}$ daily, fludrocortisone $0.15 \mathrm{mg}$ daily, and sodium chloride $3 \mathrm{~g}$ daily. Blood pressure was normal. During the first year of life she remained well but linear growth was slow, both height and weight being well below the 3rd centile. In her second year, doubt regarding the diagnosis was raised and at $2 \cdot 16$ years dexamethasone was withdrawn. Plasma cortisol remained normal and the urinary 17-oxosteroids were persistently $0.5-0.9 \mathrm{mg} / 24 \mathrm{~h}(1.74$ $3 \cdot 12 \mu \mathrm{mol} / 24 \mathrm{~h}$ ). At $3 \cdot 75$ years a corticotrophin stimulation test gave entirely normal results as judged by both plasma and urinary steroid values. Bone age was then equal to chronological age. All drugs other than oral sodium chloride $12 \mathrm{~g}$ daily were discontinued when she was aged 4 years and this was the only therapy until reinvestigation at age $8 \cdot 25$ years. Her height was then $114 \mathrm{~cm}$ ( $<3 \mathrm{rd}$ centile), weight $19 \cdot 1 \mathrm{~kg}$, and the bone age $8 \cdot 1$ years (Fig. 1b).

Case 3. A boy was the second of twins born by breech delivery at 40 weeks (10 February 1964). Birthweight $1.98 \mathrm{~kg}$. Vomiting of feeds started on the 10th day by which time the serum electrolytes showed that the sodium and chloride concentration was depressed and the serum potassium raised. Urinary steroid metabolite output per $24 \mathrm{~h}$ were 17 -oxosteroids $1.4 \mathrm{mg}$ (4.86 $\mu \mathrm{mol}), 17-$ hydroxycorticosteroids $1.9 \mathrm{mg},(6.59$ $\mu \mathrm{mol})$, and pregnanetriol $0.05 \mathrm{mg}(0.15 \mu \mathrm{mol})$. Rapid 


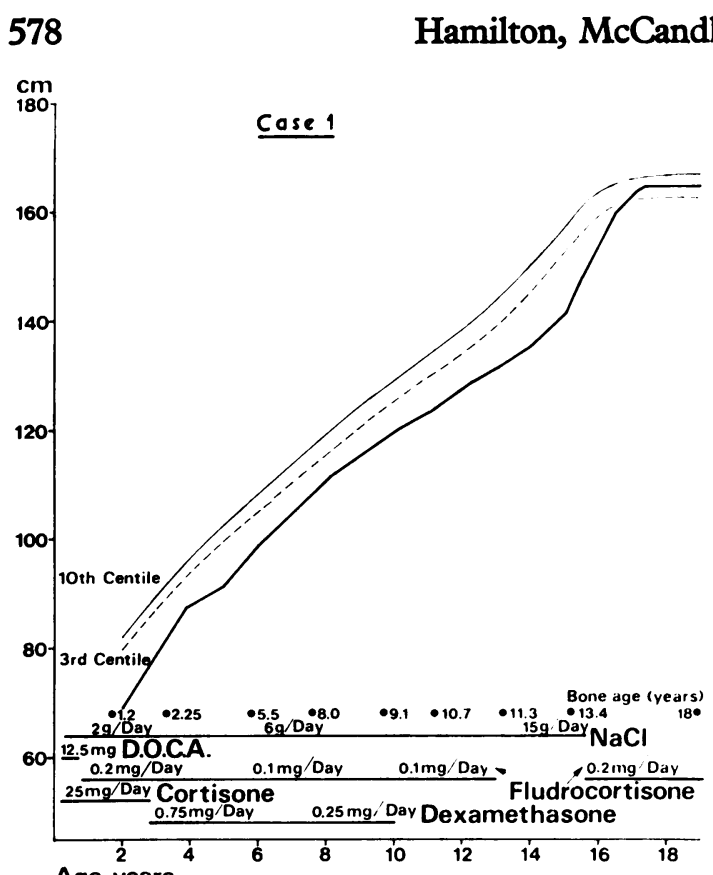

Age, years

(a)

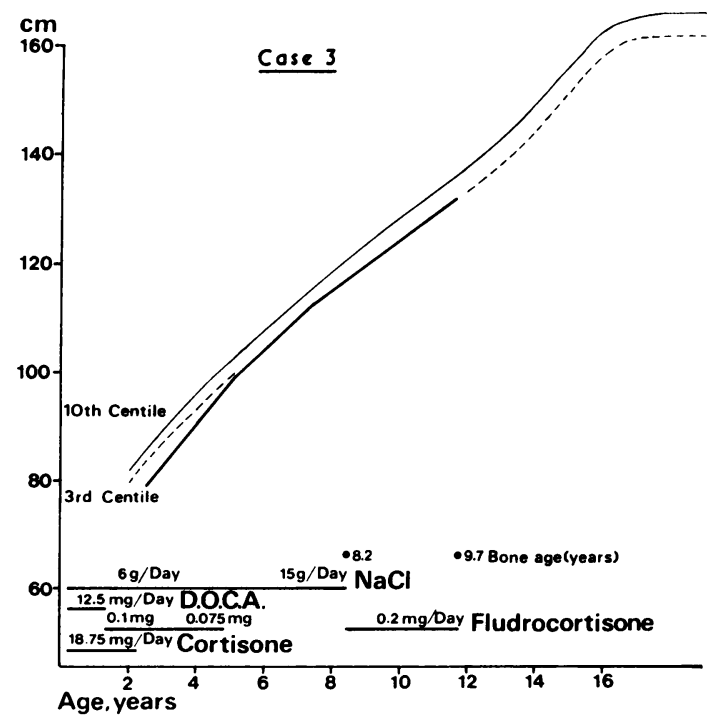

(c)

Fig. 1 (a, b, c).-Growth and bone age in the 3 sibs related to treatment regimens.

deterioration despite normal saline given intravenously necessitated the following therapeutic regimen: dexamethasone $0.25 \mathrm{mg}$ three times daily, fludrocortisone $0.05 \mathrm{mg}$ twice daily, sodium chloride $1 \mathrm{~g}$ daily with intramuscular DOCA $12.5 \mathrm{mg}$ daily. On this regimen

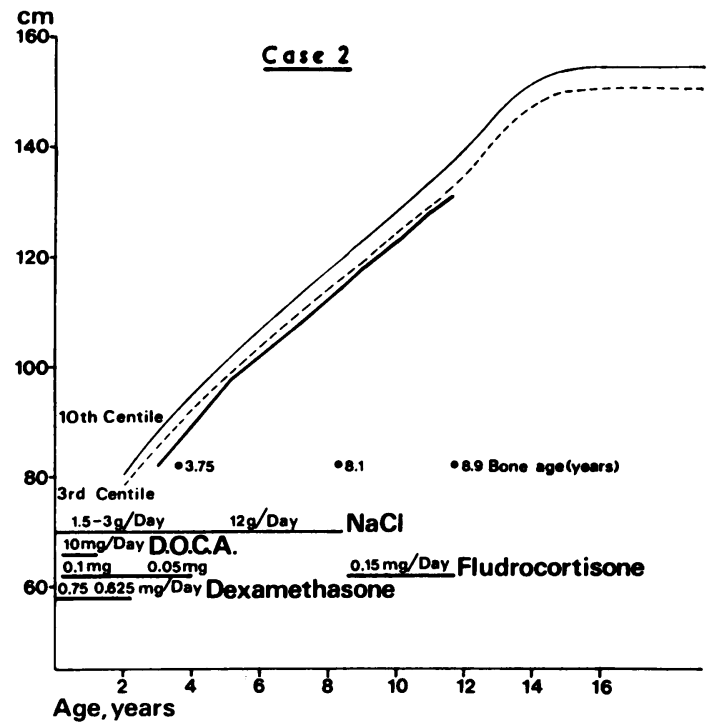

(b)

the blood pressure was maintained around $75 / 60 \mathrm{mmHg}$. At age 4 months due to difficulty in maintaining normal serum electrolyte concentrations dexamathasone was replaced with cortisone acetate $6.25 \mathrm{mg}$ three times daily.

At the age of 6 months he required surgery for bilateral glaucoma (Clements, 1971). However, his general progress was reasonable though height and weight were both below the 3rd centile. DOCA was gradually reduced over the following 9 months and finally discontinued at the age of 13 months. During the second year of life cortisone acetate was also gradually reduced and finally withdrawn at age $2 \cdot 16$ years. He was then having fludrocortisone $0.025 \mathrm{mg}$ three times daily and oral sodium chloride $2 \mathrm{~g}$ thrice daily. Daily excretion of urinary steroid metabolites was then normal.

At age 3 years there was a normal adrenal response to an intramuscular corticotrophin stimulation test as judged on plasma and urinary steroid levels. There then followed a period of accelerated growth and at 4. 75 years he was on the 3rd centile for height. Fludrocortisone was withdrawn and he was maintained on sodium chloride $5 \mathrm{~g}$ three times daily alone, his blood pressure remaining normal. He was reinvestigated at age 8.25 years having had no steroid therapy for the previous 3.5 years. At the time of reinvestigation height was $117 \mathrm{~cm}$ (3rd centile), weight $18 \cdot 75 \mathrm{~kg}$ (3rd centile), and bone age $8 \cdot 2$ years (Fig. 1c).

\section{Methods}

Sodium balance studies were carried out with the co-operation of the dietitian (Mrs. J. Clarke) and the hospital biochemist (Dr. R. W. Logan). Duplicate daily meals and portions of uneaten food were assayed for sodium content and appropriate deductions made. The corticotrophin adrenal stimulation test was performed according to Clayton, Edwards, and Renwick 
(1963) and the group urinary steroid metabolites assayed according to the MRC recommendations (Medical Research Council, 1963). Urinary free aldosterone was measured by Brooks's (1960) method and free deoxycorticosterone (DOC); corticosterone (B), 18-hydroxycorticosteroid (18-OH-B), and 11-dehydrocorticosterone (A) after initial extraction and separation on paper (Zaffaroni and Bush C systems) were assayed by GLC (flame ionization detection) after periodic oxidative conversion to $17 \beta$-carboxylic acid and methyl ester formation with diazomethane (Merits, 1962).

Recovery rates up to the third paper chromatograph for aldosterone and to GLC injection for compounds B and DOC were estimated on the radioactivity in aliquots of the final extracts, against that initially added to the urine $\left({ }^{8} \mathrm{H}-7 \alpha\right.$-aldosterone $\left.(100000 \mathrm{dpm})\right), 4-{ }^{14} \mathrm{C}$-corticosterone (10000 dpm), and $4^{-14} \mathrm{C}$-deoxycorticosterone $(10000 \mathrm{dpm}))$. A mean recovery rate was used in the calculations for compounds $A$ and 18-OH-B. The GLC column $(213 \mathrm{~cm} \times 5 \mathrm{~mm})$ was packed with $0.75 \%$ SE 30 coated on silanized 120-140 mesh Gas Chrom Q.

The methods used for the extraction of urinary tetrahydrocortisol (THF), allotetrahydrocortisol (allo-THF), tetrahydrocortisone (THB), allotetrahydrocorticosterone (allo-THB), and 18-hydroxytetrahydro-11-dehydrocorticosterone (18-OH-THA) were essentially those of David et al. (1968). A recovery rate was not applied. The final quantitation of the metabolites of cortisol and cortisone was by the blue tetrazolium reaction using a twice purified blue tetrazolium preparation alkaline solution (Visser and Cost, 1964). The metabolites of compounds $A, B$, and 18-OHA were quantitated by GLC of their MO-TMSi derivatives (methyloxime-trimethylsilyl ether) after the method of Gardiner and Herning (1966) against a reliable standard of each compound injected on to the column 15 minutes after the respective test samples.

According to David et al. (1968) 18-OHTHA is isolated in pure form by their method (confirmed by infrared spectroscopy). We have extracted from 101 of our patients' urine $2.648 \mathrm{mg}$ of the substance identified by these authors as 18-OHTHA. We were therefore able to prepare by weight a standard preparation for GLC quantitation of the compound as extracted from the individual patients' 24-hour urine collections.

\section{Results}

The elder boy was investigated in December 1971, the twins in May 1972. Since the investigations on the older sib yielded positive results indicating the nature of the disease, we could omit several of the tests on the twins. Only the older boy had growth hormone reserve assayed using the insulin-induced hypoglycaemia provocation test $(0.1$ units $/ \mathrm{kg})$. Table I shows that there was no lack of growth hormone in response to hypoglycaemia and it might be judged that the small rise in the plasma cortisol level $(6 \mu \mathrm{g} / 100 \mathrm{ml} ; 165 \cdot 6$ nmol/1) reflects the long continued pituitary/adrenal suppression from the glucocorticosteroid therapy. However, the levels of cortisol obtained indicate that the adrenal glands were capable of elaborating cortisol. The results of the corticotrophin adrenal stimulation test on the 3 sibs are shown in Table II.

TABLE I

Growth hormone assay in Case 1

\begin{tabular}{|c|c|c|c|}
\hline $\begin{array}{l}\text { Time } \\
\text { (min) }\end{array}$ & $\begin{array}{l}\text { Plasma glucose } \\
(\mathrm{mg} / 100 \mathrm{ml})\end{array}$ & $\begin{array}{l}\text { Plasma cortisol } \\
(\mu \mathrm{g} / 100 \mathrm{ml})\end{array}$ & $\begin{array}{c}\text { Growth hormone } \\
(\mathrm{ng} / \mathrm{ml})\end{array}$ \\
\hline $\begin{array}{r}0 \\
15 \\
30 \\
45 \\
60 \\
90 \\
120\end{array}$ & $\begin{array}{l}64 \\
42 \\
45 \\
20 \\
62 \\
60 \\
64\end{array}$ & $\begin{array}{l}29 \\
30 \\
35 \\
34 \\
27 \\
20 \\
20\end{array}$ & $\begin{array}{r}5 \\
5 \\
7 \\
>100 \\
40 \\
9 \\
15\end{array}$ \\
\hline
\end{tabular}

TABLE II

Urinary steroid metabolites after corticotrophin administration

\begin{tabular}{|c|c|c|c|c|c|c|c|c|c|c|c|c|}
\hline \multirow[b]{3}{*}{ Case no. * } & \multicolumn{12}{|c|}{ Urinary steroid metabolites mg/24 h ( $\mathrm{mmol} / 24 \mathrm{~h})$} \\
\hline & \multicolumn{3}{|c|}{ 17-oxosteroids } & \multicolumn{3}{|c|}{ 17-oxogenicsteroid } & \multicolumn{3}{|c|}{ 17-hydroxycorticosteroid } & \multicolumn{3}{|c|}{ Pregnanetriol } \\
\hline & 1 & 2 & 3 & $\mathbf{1}$ & 2 & 3 & 1 & 2 & 3 & 1 & 2 & 3 \\
\hline $\begin{array}{l}\text { Basal day } \\
\text { 3rd day of ACTH } \\
\text { stimulation ( } 40 \mathrm{mg} \\
\text { IM ACTH gel) }\end{array}$ & $\begin{array}{c}7 \cdot 2 \\
(24 \cdot 98)\end{array}$ & $\begin{array}{c}3 \cdot 17 \\
(11 \cdot 00)\end{array}$ & $\begin{array}{c}1 \cdot 71 \\
(5 \cdot 93) \\
\\
1 \cdot 17 \\
(4 \cdot 06)\end{array}$ & $\begin{array}{c}7 \cdot 1 \\
(24 \cdot 64)\end{array}$ & $\begin{array}{c}0 \cdot 45 \\
(1 \cdot 56) \\
\\
2 \cdot 14 \\
(7 \cdot 43)\end{array}$ & $\begin{array}{c}0 \cdot 90 \\
(3 \cdot 12)\end{array}$ & $\begin{array}{c}7 \cdot 9 \\
(27 \cdot 41)\end{array}$ & $\begin{array}{c}5 \cdot 11 \\
(7 \cdot 75)\end{array}$ & $\begin{array}{c}4 \cdot 9 \\
(17 \cdot 00)\end{array}$ & $\begin{array}{c}0.3 \\
(0.89) \\
\\
0.6 \\
(1 \cdot 78)\end{array}$ & $\begin{array}{c}0 \cdot 1 \\
(0 \cdot 3) \\
\\
0 \cdot 5 \\
(1 \cdot 49)\end{array}$ & $\begin{array}{c}0 \cdot 21 \\
(0 \cdot 62)\end{array}$ \\
\hline
\end{tabular}

$\star 1$, male aged $15 ; 2$, female aged $8 ; 3$, male aged 8 . 
Basal and poststimulation levels of the urinary 17-oxogenic and total hydroxycorticosteroids are low, and probably represent the effects of the administered glucocorticosteroids. Significantly, the urinary pregnanetriol levels were normally low and this fact is against a diagnosis of congenital adrenal hyperplasia due to 21-hydroxylase deficiency.

In Table III are the results of the sodium balance studies with the serum electrolyte concentrations. It is clear that all 3 children lost more sodium in the urine than they ingested and with progressive salt restriction the serum sodium reflected the continuous sodium loss. Towards the end of the salt-restriction periods both boys experienced an adrenal crisis. The effects of the progressive hypovolaemia on heart size in the elder boy is shown in Fig. 2. His plasma angiotensin II levels were assayed in the basal state and after salt restriction (Table IV). The enormously high basal value is not maintained during salt restriction but

TABLE III

Sodium balance studies

\begin{tabular}{|c|c|c|c|c|c|c|c|c|c|c|c|c|c|c|c|c|}
\hline & \multirow[b]{3}{*}{ Case no. } & \multicolumn{6}{|c|}{$\mathrm{mmol} / \mathrm{day}$} & \multicolumn{9}{|c|}{ Serum electrolytes (mmol/1) } \\
\hline & & \multicolumn{3}{|c|}{ Dietary sodium } & \multicolumn{3}{|c|}{ Urinary sodium } & \multicolumn{3}{|c|}{ Sodium } & \multicolumn{3}{|c|}{ Potassium } & \multicolumn{3}{|c|}{ Chloride } \\
\hline & & 1 & 2 & 3 & 1 & 2 & 3 & 1 & 2 & 3 & 1 & 2 & 3 & 1 & 2 & 3 \\
\hline $\begin{array}{c}\text { Basal day } \\
\text { Test day } \\
\text { " } \\
\text { " } \\
\text { " } \\
\text { " }\end{array}$ & $\begin{array}{l}1 \\
2 \\
3 \\
4 \\
5 \\
6 \\
7\end{array}$ & $\begin{array}{r}225 \\
168 \\
56 \\
56 \\
56 \\
17 \\
17 \\
17\end{array}$ & $\begin{array}{r}136 \\
94 \\
84 \\
17 \\
17 \\
17 \\
17 \\
17\end{array}$ & $\begin{array}{r}136 \\
94 \\
83 \\
17 \\
17 \\
17 \\
17 \\
17\end{array}$ & $\begin{array}{r}536 \\
197 \\
65 \\
140 \\
65 \\
95 \\
98 \\
140\end{array}$ & $\begin{array}{r}149 \\
136 \\
157 \\
176 \\
130 \\
135 \\
54 \\
74\end{array}$ & $\begin{array}{r}119 \\
127 \\
241 \\
140 \\
122 \\
66 \\
56 \\
74\end{array}$ & $\begin{array}{l}137 \\
140 \\
\\
\\
131 \\
126 \\
126 \\
126 \\
126\end{array}$ & $\begin{array}{r}141 \\
132 \\
\\
127 \\
\\
129\end{array}$ & $\begin{array}{r}138 \\
131 \\
\\
133 \\
\\
130\end{array}$ & $\begin{array}{l}3 \cdot 9 \\
4 \cdot 6 \\
\\
5 \cdot 0 \\
4 \cdot 8 \\
5 \cdot 0 \\
4 \cdot 8 \\
5 \cdot 0\end{array}$ & $\begin{array}{l}3 \cdot 6 \\
5 \cdot 2 \\
5 \cdot 0 \\
5 \cdot 6\end{array}$ & $\begin{array}{l}3 \cdot 4 \\
3 \cdot 7 \\
4 \cdot 6 \\
4 \cdot 2\end{array}$ & $\begin{array}{l}104 \\
104 \\
\\
95 \\
95 \\
91 \\
91 \\
95\end{array}$ & $\begin{array}{r}105 \\
99 \\
96 \\
96\end{array}$ & $\begin{array}{r}102 \\
98 \\
98 \\
100\end{array}$ \\
\hline
\end{tabular}

TABLE IV

Plasma angiotensin II in reponse to salt restriction in Case 1

\begin{tabular}{|c|c|c|c|c|c|c|}
\hline \multirow[b]{2}{*}{ Test day } & \multicolumn{2}{|c|}{$\mathrm{mmol} /$ day } & \multicolumn{3}{|c|}{$\begin{array}{l}\text { Serum electrolytes } \\
(\mathrm{mmol} / \mathrm{l})\end{array}$} & \multirow{2}{*}{$\frac{\begin{array}{c}\mathrm{pg} / \mathrm{ml} \\
(\mathrm{pmol} / \mathrm{l})\end{array}}{\text { Angiotensin } \mathrm{II}^{\star}}$} \\
\hline & Intake & Urinary & $\mathrm{Na}^{+}$ & $\mathbf{K}^{+}$ & $\mathrm{Cl}^{-}$ & \\
\hline 1 & 168 & 197 & 140 & $4 \cdot 6$ & 104 & $\begin{array}{l}1132 \\
(1088)\end{array}$ \\
\hline 4 & 56 & 65 & 126 & $4 \cdot 8$ & 95 & $\begin{array}{l}720 \\
(692)\end{array}$ \\
\hline
\end{tabular}

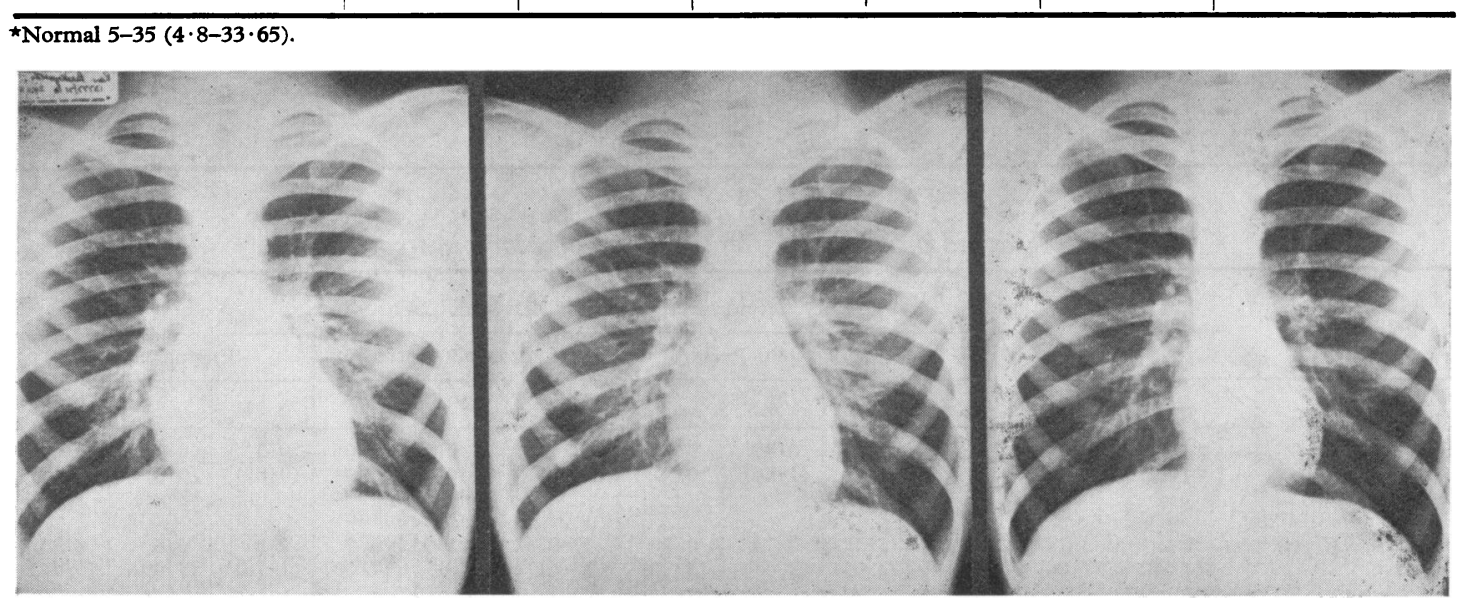

Fig. 2.-Case 1. Progressive microcardia occurring during salt restriction. 
this may be accounted for by the fact that we did observe a slight increase in the total urinary hydroxycorticosteroids with salt-restriction, and it may be that the mineralocorticoid activity of increased cortisol had a protective effect at renal tubular level. This fact may account also for the maintenance of near normal serum potassium levels.

The values shown in Table $\mathrm{V}$ for the urinary metabolites of cortisol are from the urine of the third day of ACTH stimulation, while the values in Table VI for the mineralocorticosteroids are from the urine of the last day of maximum salt restriction. Clearly the glucocorticosteroid metabolites are present in adequate quantity indicating normal cortisol biosynthesis and metabolism. Only in the female twin was free aldosterone detectable (Table VI, $0.5 \mu \mathrm{g} / 24 \mathrm{~h}$ ), though at the lower level of sensitivity of the fluorimeter. None was detected in the 2 boys and both experienced an adrenal crisis when severely salt-restricted. According to the normal urinary values for the metabolites in the mineralocorticoid pathway (Fig. 3) listed in Table VI, our patients excreted in excess all the precursors of aldosterone up to the last stage of aldosterone synthesis. This fact supports the concept that the final enzymatic step (18dehydrogenase) in the synthesis of aldosterone is probably absent in 2 of our patients (males) and deficient in one (female).

\section{Discussion}

Salt-losing states in the newborn period are most commonly associated with congenital adrenal hyperplasia in which condition both the glucocorticosteroid and mineralocorticosteroid biosynthetic pathways are interrupted, usually by lack of C21hydroxylase. Temporary salt-losing states in which the production of cortisol is unimpaired (Russell et al., 1963) have also been recognized. Visser and Cost (1964) firmly established the clinical entity of a salt-losing state due to an inborn error of aldosterone synthesis alone without impairment of cortisol production. The following year Ulick et al. (1964) described a second possible enzyme defect in aldosterone synthesis which also results in clinical salt-loss.

In Fig. 3 the biosynthetic pathways for cortisol and aldosterone are shown with the site of action of the various enzymes in the aldosterone pathway. David et al. (1968) described 2 further examples of salt loss due to 18-dehydrogenase deficiency. We now describe 3 other sibs with clinical salt loss due to C18-dehydrogenase defect and in whom cortisol synthesis was unimpaired.

\section{TABLE V}

Urinary glucocorticoids and their metabolites $(\mu \mathrm{g} / 24 \mathrm{~h} ; \mu \mathrm{mol} / 24 \mathrm{~h})$ in urine on the third day after $A C T H$

\begin{tabular}{|c|c|c|c|c|c|}
\hline & $\mathbf{F}$ & $\mathbf{E}$ & THF & Allo-THF & THE \\
\hline $\begin{array}{l}\text { Case } 1 \\
\text { Case } 2 \\
\text { Case } 3\end{array}$ & $\begin{array}{c}840 \\
(2 \cdot 32) \\
420 \\
(1 \cdot 16) \\
360 \\
(0 \cdot 99)\end{array}$ & $\begin{array}{c}140 \\
(0 \cdot 39) \\
90 \\
(0 \cdot 25) \\
110 \\
(0 \cdot 31)\end{array}$ & $\begin{array}{c}940 \\
(2 \cdot 57) \\
460 \\
(1 \cdot 09) \\
400 \\
(1 \cdot 10)\end{array}$ & $\begin{array}{c}2140 \\
(5 \cdot 84) \\
1864 \\
(5 \cdot 10) \\
1688 \\
(4 \cdot 61)\end{array}$ & $\begin{array}{c}3100 \\
(8 \cdot 51) \\
2100 \\
(5 \cdot 76) \\
2240 \\
(6 \cdot 15)\end{array}$ \\
\hline
\end{tabular}

F, cortisol; E, cortisone; THF, tetrahydrocortisol; THE, tetrahydrocortisone; Allo-THF, allo-tetrahydrocortisol.

TABLE VI

Urinary 17-deoxycorticosteroids and their metabolites $(\mu g / 24 h ; \mu m o l / 24 h)$. Values from urine of maximum salt-restricted period

\begin{tabular}{|c|c|c|c|c|c|c|c|c|}
\hline & DOC & $\mathbf{B}$ & $\mathbf{A}$ & 18-OH-B & Aldo & THB & Allo-THB & 18-OH-THA \\
\hline $\begin{array}{l}\text { Case } 1 \\
\text { Case } 2 \\
\text { Case } 3 \\
\text { Normal adult }\end{array}$ & $\begin{array}{c}45 \\
(0 \cdot 14) \\
40 \\
(0 \cdot 12) \\
48 \\
(0 \cdot 15) \\
\star\end{array}$ & $\begin{array}{c}200 \\
(0.58) \\
210 \\
(0 \cdot 61) \\
190 \\
(0 \cdot 55) \\
30-80 \\
(0.08-0.23)\end{array}$ & $\begin{array}{c}90 \\
(0.26) \\
85 \\
(0.25) \\
64 \\
(0.99) \\
0-30 \\
(0-0.9)\end{array}$ & $\begin{array}{c}320 \\
(0 \cdot 98) \\
280 \\
(0 \cdot 77) \\
300 \\
(0 \cdot 83) \\
\star\end{array}$ & $\begin{array}{c}0 \\
0.5 \\
0 \\
2-6 \\
(0.06-0.36)\end{array}$ & $\begin{array}{c}260 \\
(0 \cdot 75) \\
126 \\
(0 \cdot 36) \\
118 \\
(0 \cdot 34) \\
10-36 \\
(0 \cdot 03-0 \cdot 1)\end{array}$ & $\begin{array}{c}1200 \\
(3 \cdot 42) \\
500 \\
(1 \cdot 43) \\
480 \\
(1 \cdot 37) \\
8-36 \\
(0 \cdot 02-0 \cdot 1)\end{array}$ & $\begin{array}{c}680 \\
(1 \cdot 86) \\
420 \\
(1 \cdot 15) \\
540 \\
(1 \cdot 47) \\
\star\end{array}$ \\
\hline
\end{tabular}

DOC, deoxycorticosterone; B, corticosterone; A, 11-dehydro corticosterone; 18-OH-B, 18-hydroxycorticosterone; Aldo, aldosterone;

THB, tetrahydrocorticosterone; Allo-THB, Allo-tetrahydrocorticosterone; 18-OH-THA, tetrahydro-18-hydroxy-11-dehydrocorticosterone. $\star$ Reliable data not available. 


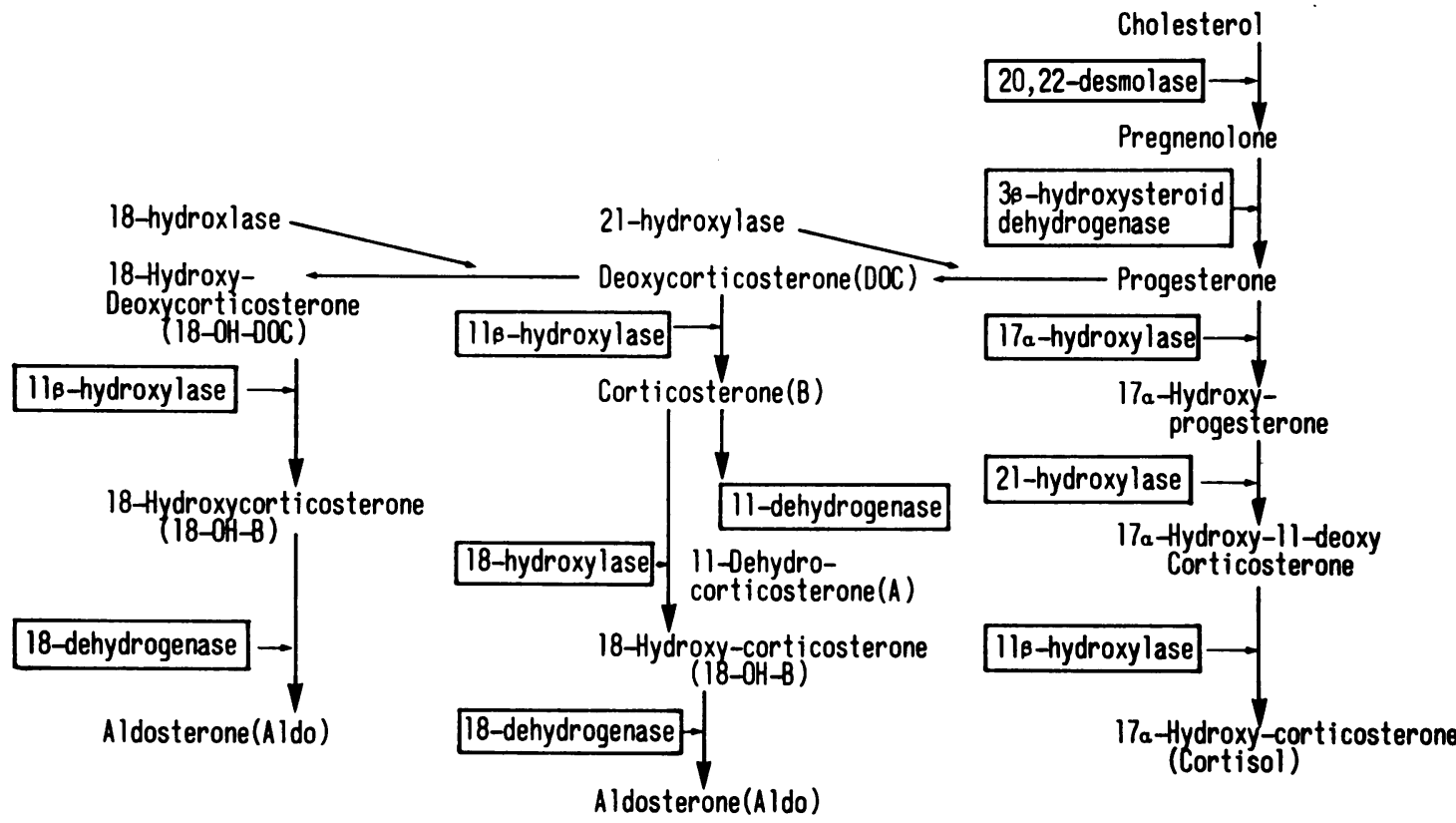

FIG. 3.-Biosynthetic pathways from cholesterol to cortisol and aldosterone. Note the 18-hydroxy pathway to aldosterone (not yet fully established).

It is now becoming clear that this type of saltlosing syndrome is a distinct clinical entity. Common to those cases already described and our 3 is failure of linear growth. While it can be argued that the glucocorticosteroid therapy in our cases was undoubtedly contributory to growth retardation, smallness of stature seems to be a feature of the syndrome. A second fact is that the serum electrolytes need not necessarily show the gross changes of marked hyponatraemia and hyperkalaemia characteristic of the salt-losing form of the adrenogenital syndrome. One case described by David et al. (1968) had near normal serum electrolyte concentrations despite salt loss, while in our patients, though the serum sodium fell to critically low levels, the serum potassium level was not remarkably high $(7.9 \mathrm{mmol} / \mathrm{l})$. This is in contrast to our experience with comparable clinical salt loss in patients with congenital adrenal hyperplasia in whom serum potassium levels in excess of $9 \mathrm{mmol} / 1$ are frequently encountered. We cannot explain the finding but perhaps the mineralocorticosteroid activity of the normally present cortisol also exerts a 'potassiumregulating' influence.

Urine analyses have shown (Table VI) that in our patients there is no lack of cortisol, but that aldosterone is absent ( 2 males) or reduced ( 1 female). Reciprocal to the reduction in urinary aldosterone there was an increase in the excretion of compounds A, B, THB, allo-THB, THA, DOC, 18-OH-B, and 18-OH-THA. Thus with the final step to aldosterone synthesis blocked by lack of the enzyme C18-dehydrogenase, the precursors increased, and while some of them appeared in the urine in free form (compounds A, B, DOC, and 18-OH-B) others were metabolized to their tetrahydrometabolites (Table VII).

\section{TABLE VII}

Intermediate compounds in the mineralocorticoid pathway and their urinary metabolites

\begin{tabular}{|c|c|}
\hline $\begin{array}{l}\text { Compound } \\
\text { Deoxycorticosterone } \\
\text { Corticosterone } \\
\text { 18-Hydroxycorticosterone- } \\
\text { 18-Hydroxy-11-dehydro- } \\
\text { corticosterone } \\
\text { Aldosterone }\end{array}$ & $\begin{array}{c}\text { Urinary metabolite } \\
\longrightarrow \text { tetrahydrodeoxycorticosterone } \\
\text { (THDOC) } \\
\longrightarrow \text { tetrahydrocorticosterone (THB) } \\
\longrightarrow \text { tetrahydro-18-hydroxycorticoste- } \\
\text { rone (18-OH-THB) } \\
\text { tetrahydro-18-hydroxy-11- } \\
\text { dehydro-corticosterone } \\
\text { (18-OH-THA) } \\
\longrightarrow \text { tetrahydroaldosterone (TH Aldo) }\end{array}$ \\
\hline
\end{tabular}

It is of interest that the plasma angiotensin II level in Case 1 was higher when he was on a high salt intake. As salt restriction proceeded the plasma level of angiotensin II fell, though not to within 
the normal range. One of the cases of David et al. (1968) in whom the assay was done also had a high plasma angiotensin II level.

Renin is produced by the cells of the juxtaglomerular apparatus in the wall of the afferent arteriole. In the circulation it acts enzymatically on angiotensin elaborated by the liver, to form angiotensin $I$. This is then converted by a 'converting enzyme' to angiotensin II which later is a major factor stimulating the production of aldosterone. The initial stimulus to renin production is a falling sodium concentration in the distal tubule resulting also in a reduced sodium concentration at the macula densa, part of the juxtaglomerular apparatus.

It could be argued that in our patient the initially high angiotensin II level, when he was ingesting $168 \mathrm{mmol}$ sodium daily and drinking copiously, resulted in a glomerular filtrate relatively low in sodium concentration. As salt deprivation continued less fluid was imbibed, less urine was voided, but the urinary sodium loss remained greater than that ingested. The glomerular filtrate therefore relative to sodium could have become more concentrated with the effect of reducing renin production. If this is the mechanism by which the plasma angiotensin II levels fell in our patient, then it is an argument against administering added salt to the therapeutic regimen of patients who are salt-losers for any reason. It seems more rational to increase sodium absorption using fludrocortisone so as to avoid a high filtered water load. Little work has been done in paediatric practice on angiotensin II levels during treatment of the salt-losing form of congenital adrenal hyperplasia, congenital adrenal hypoplasia, or this newly recognized group of patients with enzymatic defects in the biosynthesis of aldosterone. However, it appears from the scant information available that high plasma levels of angiotensin II are associated with salt-loss. This raises the question whether rational teatment for this syndrome and perhaps for other salt-losing states, is deoxycorticosterone pivalate (PercortenCIBA) ${ }^{\star}$ plus added dietary salt (which implies a continuing salt-losing state), or fludrocortisone alone, thereby aiming at the prevention of salt-loss. It could be argued that the glucocorticoid action of fludrocortisone may suppress both corticotrophin and growth hormone, but in the dosage which we have found necessary to give to prevent salt-loss, there

*Organon preparation of DOCA withdrawn from U.K. market. has been no evidence of growth restriction (Fig. $1 \mathrm{a}, \mathrm{b}, \mathrm{c})$ nor of corticotrophin lack.

\section{Progress}

At the time of writing (September 1975) Case 1 has now been on fludrocortisone $0.1 \mathrm{mg}$ twice daily for 3.5 years. At 15.4 years his height was $144.8 \mathrm{~cm}$ ( $>3$ rd centile) and weight $31.8 \mathrm{~kg}$ ( $>3 \mathrm{rd}$ centile). Pubic hair and deepening of the voice were noted at $15 \cdot 5$ years. At $19 \cdot 13$ years his height is now $164 \cdot 9 \mathrm{~cm}$ (<3rd centile), his weight $49 \cdot 2 \mathrm{~kg}$, and bone age 18 years. Case 2 has now been on fludrocortisone $0.15 \mathrm{mg}$ daily for 3.3 years. The blood pressure and serum electrolytes have remainremained normal. Her present height at $11 \cdot 7$ years is $130.7 \mathrm{~cm}$ ( $>3 \mathrm{rd}$ centile), weight $27.9 \mathrm{~kg}$, and bone age 8.9 years. Case 3 has been on fludrocortisone $0.1 \mathrm{mg}$ twice daily alone for $3 \cdot 3$ years. At 11.7 years his height is $131.8 \mathrm{~cm}$ (3rd centile) weight $27 \cdot 2 \mathrm{~kg}$, and bone age $9 \cdot 7$ years. None of the children have experienced salt-losing symptoms even during moderately severe upper respiratory infections.

\section{REFERENCES}

Brooks, R. V. (1960). A method for the determination of aldosterone. Quantitative Paper Chromatography of Steroids. Memoirs of the Society for Endocrinology, No. 8, p. 9. Ed. by D. Abelson and R. V. Brooks. Cambridge University Press.

Clayton, B. E., Edwards, R. W. H., and Renwick, A. G. C. (1963). Adrenal function in children. Archives of Disease in Childhood, 38, 49.

Clements, D. B. (1971). Adrenogenital syndrome and buphthalmos. British fournal of Ophthalmology, 55, 275.

David, R., Golan, S., and Drucker, W. (1968). Familial aldosterone deficiency: enzyme defect, diagnosis and clinical course. Pediatrics, 41, 403.

Gardiner, W. L., and Herning, E. C. (1966). Gas-liquid chromatographic separation of $\mathrm{C}_{19}$ and $\mathrm{C}_{21}$ human urinary steroids by a new procedure. Biochimica et Biophysica Acta, 115, 524.

Medical Research Council (1963). A standard method of estimating 17-oxosteroids and total 17-oxogenic steroids. Lancet, 1, 1415.

Merits, I. (1962). Gas-liquid chromatography of adrenal cortical steroid hormones. Fournal of Lipid Research, 3, 126.

Russell, A., Levin, B., Sinclair, L., and Oberholzer, V. G. (1963). A reversible salt-wasting syndrome of the newborn and infant. Archives of Disease in Childhood, 38, 313.

Ulick, S., Gautier, E., Vetter, K. K., Markello, J. R., Yaffe, S., and Lowe, C. U. (1964). An aldosterone biosynthetic defect in a salt-losing disorder. Fournal of Clinical Endocrinology, 24, 669.

Visser, H. K. A., and Cost, W. S. (1964). A new hereditary defect in the biosynthesis of aldosterone: urinary $\mathrm{C}_{21}$-corticosteroid pattern in three related patients with a salt-losing syndrome, suggesting an 18-oxidation defect. Acta Endocrinologica, 47, 589.

Correspondence to Dr. W. Hamilton, University Department of Child Health, Royal Hospital for Sick Children, Yorkhill, Glasgow G3 8SJ. 